\title{
STRENGTH ESTIMATION OF CERAMIC/METAL JOINTS WITH VARIOUS INTERLAYER THICKNESS
}

\author{
M. Takahashi ${ }^{1}$, N. Okabe ${ }^{1}$, X. Zhu ${ }^{1}$ and K. Kagawa ${ }^{2}$ \\ ${ }^{1}$ Department of Mechanical Engineering, Ehime University, \\ Bunkyo-cho, Matsuyama, 790-8577, JP \\ ${ }^{2}$ Honda Motor Co., Ltd., Minami-Aoyama, Minato-ku, Tokyo, JP
}

\begin{abstract}
The residual stress, which generated by thermal expansion coefficient mismatch between ceramics and metals, is an important problem on strength in ceramic/metal joints. An interlayer, which is a ductile metal, is inserted between ceramics and metal in order to relax the residual stress. In this study, first of all, the analysis of the residual stress produced in joint-cooling process and 4-point bending tests were carried out. Next, from a viewpoint of experimental and fracture mechanics, the effects of interlayer thickness on joint strength in ceramic/metal joints were discussed considering the superposed stress distribution of the residual stress and the bending stress. In addition, the estimation of joint strength was tried to do from viewpoints of fracture mechanics and probability of strength by considering the residual stress, size and position of potential defects in the ceramics. From the above-mentioned, it is found that the optimum thickness is $0.2 \mathrm{~mm}$ in this specimen.
\end{abstract}

\section{INTRODUCTION}

Ceramic/metal joint is an excellent technology to carry out the application expansion of the monolithic ceramics, which are brittle materials. Especially, "active-metal" brazing method using Ag-Cu-Ti is applied actively to the chamber of the vacuum valve, the semiconductor plate and parts of automobile, and is expected very much as the structural material and the function material. However, though this ceramic/metal joints technology is not performed academic proof enough to safety and reliability, has already been used as many joint structure products [1,2]. Some of joint structure products have caused some troubles and accidents by the use at a long period. Therefore, The maintenance of the design standard and the establishment of the strength evaluation concerning safety and reliability are required immediately from a long-term reliability viewpoint.

A major problem in ceramic/metal joints is thermal expansion coefficient mismatch between ceramics and metal. This thermal expansion coefficient mismatch causes serious residual stresses at the interface of the ceramic/metal joints, which are generated during joint-cooling process. Then, an interlayer, which is ductile metal such as copper, nickel and so on, is inserted between ceramics and metal in order to relax the residual stress. It should be considered that the interlayer thickness has significant influence on the joint strength with considering the residual stress.

In this study, first of all, the analysis of the residual stress produced in joint-cooling process and 4-point bending tests were carried out. Next, from a viewpoint of experimental and fracture mechanics, the effects of interlayer thickness on joint strength in ceramic/metal joints were discussed considering the superposed stress distribution of the residual stress and the bending stress. The relation between strength and the frac- 
ture morphology of ceramic/metal joints specimen with various interlayer thickness, was discussed from a viewpoint of fracture mechanics. Furthermore, the estimation of joint strength was tried to do from a viewpoint of fracture mechanics and probability of strength, by considering the residual stress, size and position of the potential defects.

\section{EXPERIMENTAL PROCEDURE}

\section{Materials and Specimens}

A test specimen is the joint of pressureless-sintered silicon nitride $\left(\hat{a}-\mathrm{Si}_{3} \mathrm{~N}_{4}\right)$ and austenitic stainless steel (SUS304), with the interlayer of copper $\left(>99.95 \% \mathrm{Cu},<0.02 \% \mathrm{O}_{2}\right)$ in order to relax the residual stress produced during the joint-cooling process. This specimen is made by an "active-metal' brazing method using $\mathrm{Ag}-\mathrm{Cu}-\mathrm{Ti}$. The thickness of the brazing layer is $50 \mathrm{i} \mathrm{m}$. The shape and size of the test specimen is shown in Figure 1. The mechanical properties and physical characteristics are shown Table 1 . The conditions of brazing are shown in Table 2.

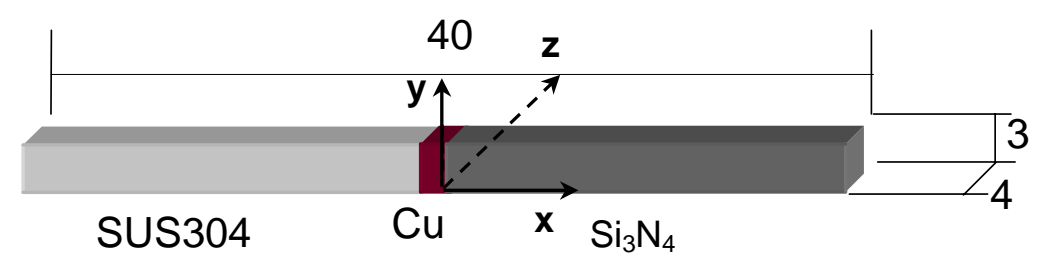

Figure 1: Shape of ceramic/metal joints specimen (mm)

TABLE 1

MECHANICAL PROPERTIES AND PHYSICAL CHARACTERISTICS OF MATERIALS AT ROOM TEMPERATURE

\begin{tabular}{|c|c|c|c|c|}
\hline Material & $\begin{array}{c}\text { Young's } \\
\text { modulus } \\
\mathrm{E} \\
(\mathrm{MPa})\end{array}$ & $\begin{array}{c}\text { Poisson's } \\
\text { ratio } \\
\mathbf{i}\end{array}$ & $\begin{array}{c}\text { Coefficient of } \\
\text { expansion } \\
\text { á } \\
\left(\times 10^{-6} / \mathrm{K}\right)\end{array}$ & $\begin{array}{c}\text { Tensile } \\
\text { strength } \\
\text { óT } \\
(\mathrm{MPa})\end{array}$ \\
\hline $\mathrm{Si}_{3} \mathrm{~N}_{4}$ & 304 & 0.27 & 3.03 & $980(4-\mathrm{P} . \mathrm{Bend})$ \\
\hline $\mathrm{Cu}$ & 108 & 0.33 & 17.7 & 237 \\
\hline $\mathrm{SUS} 304$ & 193 & 0.30 & 16.5 & 617 \\
\hline
\end{tabular}

TABLE 2

CONDITIONS OF BRAZING

\begin{tabular}{|c|c|}
\hline Brazing filler & Ti-Ag-Cu (thickness of 50 ìm) \\
\hline Joining temperature & $850^{\circ} \mathrm{C}$ \\
\hline Atmosphere & Vacuum, $1.33(\mathrm{mPa})$ \\
\hline Interlayer & $\mathrm{Cu}$ (thickness of $0.05,0.1,0.2,0.3 \mathrm{~mm})$ \\
\hline Holding time & $15(\mathrm{~min})$ \\
\hline Joining load & $49(\mathrm{kPa})$ \\
\hline
\end{tabular}

\section{Elastic-Plastic Analysis and Bending Test}

The residual stress in the joints was analyzed by the three-dimensional elastic-plastic finite-element method. The analysis model was meshed using 8-nodes and a falf-width size of 3-dimensional solid elements against the joint specimen as shown in Figure 2. There are six kinds of interlayer thicknesses such as 0.05, 0.1, 0.2, $0.3,0.5$ and $0.8 \mathrm{~mm}$. The brazing layer was not taken into consideration in the analysis model because it was very thin.

The temperature dependance of stress - strain curve, and the temperature dependance of the mechanical properties and physical characteristics of the metals were considered in the elastic-plastic analysis. 
In the joint-cooling process at high temperature range $\left(850^{\circ} \mathrm{C} \sim 550^{\circ} \mathrm{C}\right) \mathrm{Ag}$-brazing is soft and can rarely resist plastic mobility of the joint materials, so any of the ceramic and metals can freely deform and thermal residual stress should not arise. But with the joint's cooling, Ag-brazing becomes hard, and begins to bind thermal deformation of the materials, the residual stress due to the difference of the expansion coefficient between the ceramic and the metal should occur. Therefore, in this study, analysis temperature range was from $550^{\circ} \mathrm{C}$, at which the residual stress began to occur, to room temperature $\left(25^{\circ} \mathrm{C}\right)[3]$. To consider the temperature dependencies of the yield stress, the thermal expansion coefficient, Young's modulus, and the strain hardening exponent, etc., the analysis was divided from 550 to $20^{\circ} \mathrm{C}$ into five stages. And, the elasticplastic analysis was carried out in each stage by considering superposed stress, which was superposed the thermal stress of the present stage on the residual stress of the former stage. Therefore, the residual stress redistribution due to 4-point bend loading was analyzed. Also, bending strength properties of the joints were discussed considering the superposed stress of the bending stress and the residual stress.

4-point bend tests of ceramic/metal joints specimens were carried out using upper and lower spans of 10 and $30 \mathrm{~mm}$ and displacement rate of $0.5 \mathrm{~mm} / \mathrm{min}$. The bending strengths were calculated from the rupture load using the standard relationship for an elastic homogeneous beam and can be shown by the two-parameter Weibull statistics.

\section{EXPERIMENTAL RESULTS}

\section{Fracture Morphology}

As the results of observation of fracture surface, fracture morphology of ceramic/ metal joints can be classified into two kinds [4], as shown in Figure 3. The failure in ceramics of ultra neighborhood (10 50ìm) interfacial on the ceramics side is called as IC-type fracture (IC: From the Interface neighborhood to Ceramics). This is a typical fracture morphology seen in the bending test. This fracture was observed in all the interlayer thicknesses in present test. On the other hand, the failure in ceramics a little away

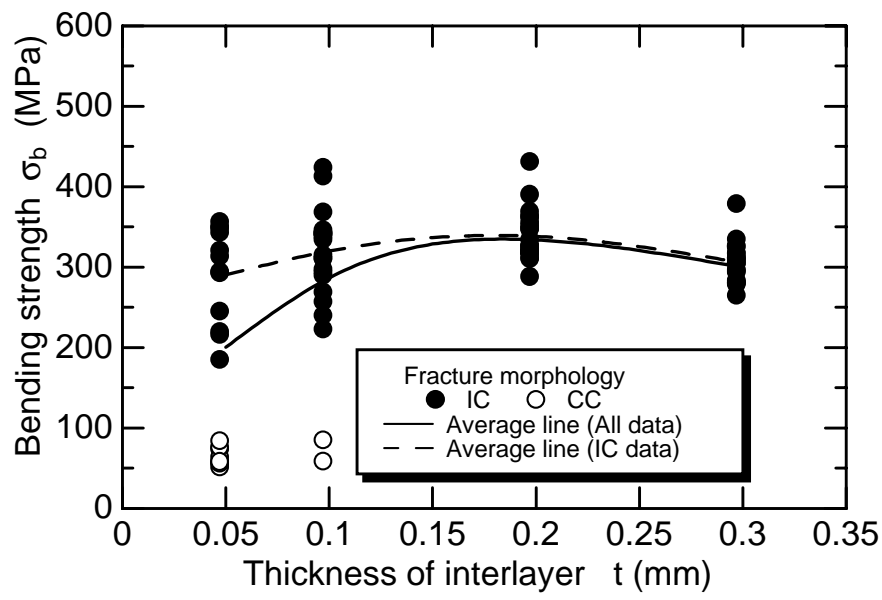

Figure 4: The relation between the interlayer thickness and strength

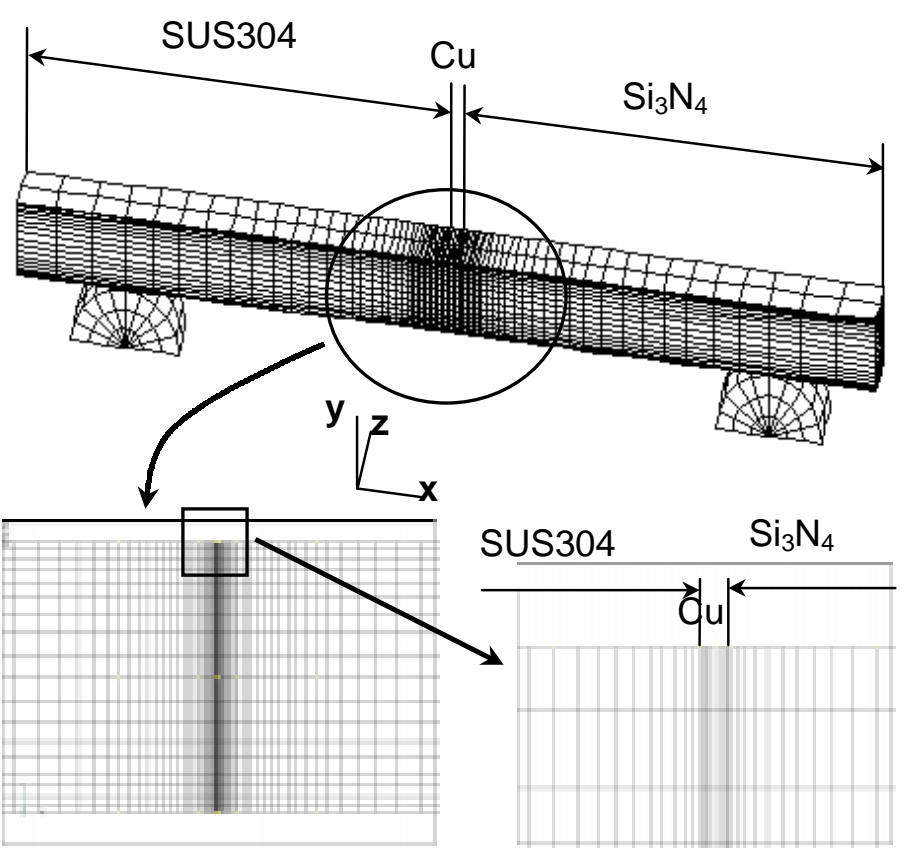

Detail of interface region by 2-dimensional display

Figure 2: 3-dimensional analysis model of ceramic/metal joint
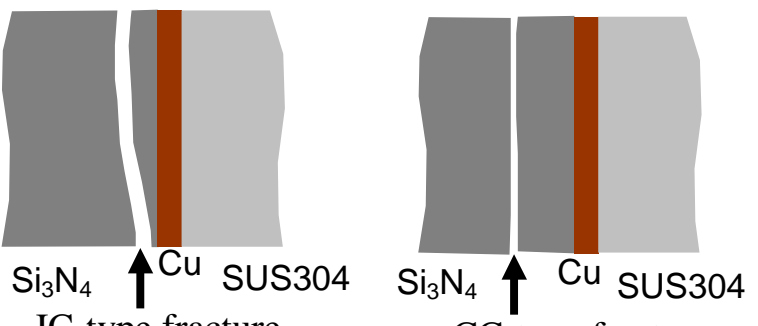

IC-type fracture

CC-type fracture

Figure 3: Illustrations of fracture morphology of ceramic/metal joint

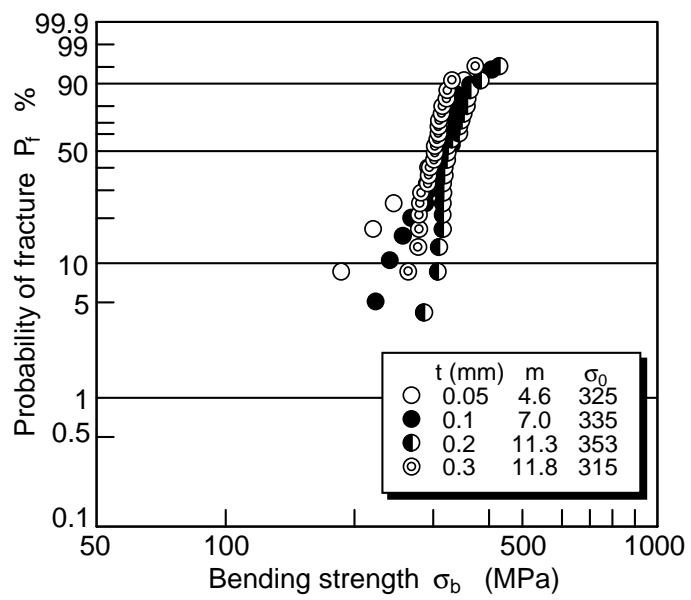

Figure 5: Weibull distribution of bending strength in each interlayer thickness 
$(>0.2 \mathrm{~mm})$ from the interface on the ceramics side is called CC-type fracture (CC: from Ceramics to Ceramics). This morphology increases only when the interlayer thickness is thin.

\section{Bending Strength of the Joints}

Based on the results of 4-point bending test, the relation between the interlayer thickness, $\mathrm{t}$ and strength, ó is shown in Figure 4. The joint strength is the maximum value at the interlayer thickness of $0.2 \mathrm{~mm}$. The appearance of strength is observed paying attention to the fracture morphology. The fracture morphology is diversified when the interlayer thickness is thin. It has found that the strength level decreases remarkably, also. Furthermore, strength of the CC-type fracture decreases remarkably.

Figure 5 shows Weibull statistics of bending strength only about IC-type fracture specimens. Scale parameter,,$_{0}$ is the maximum value at the interlayer thickness of $0.2 \mathrm{~mm}$. On the other hand, the scatter of strength shows the decreasing tendency as the Weibull parameter, $m$ increased with increasing the interlayer thickness.

\section{RESULTS OF FEM ANALYSIS}

\section{Interlayer Thickness and Equivalent Normal Residual Stress Distribution}

A fracture of ceramics occur usually from one of many initial defects existing in ceramics. And, it is necessary to consider that the fracture results from the mixed fracture mode containing mode I and mode II, because a multi-axial stress, which occurs in the joint-cooling process, acts on these initial defects. To evaluate the strength of ceramics against the mulit-axial stress state, equivalent normal stress, ó oq which is the parameter of strength, is described by the following equation:

$$
\sigma_{e q}=\sqrt{\sigma^{2}+\frac{4}{(2-v)^{2}} \tau^{2}}
$$

where, the normal stress, ó is perpendicular to the joint interface, the shear stress, ô is parallel to the joint interface. However, all stresses discussed as follows are $\mathrm{x}$ direction elements of an equivalent normal stress, subscript $\mathrm{x}$ is omitted.

Figure 6 shows the distribution of the equivalent normal residual stress, ó oq(Res $)$ on the each interlayer thickness, t. Figure 6(a) shows the residual stress distribution against $\mathrm{x}$-axis direction from the interface of ceramics.

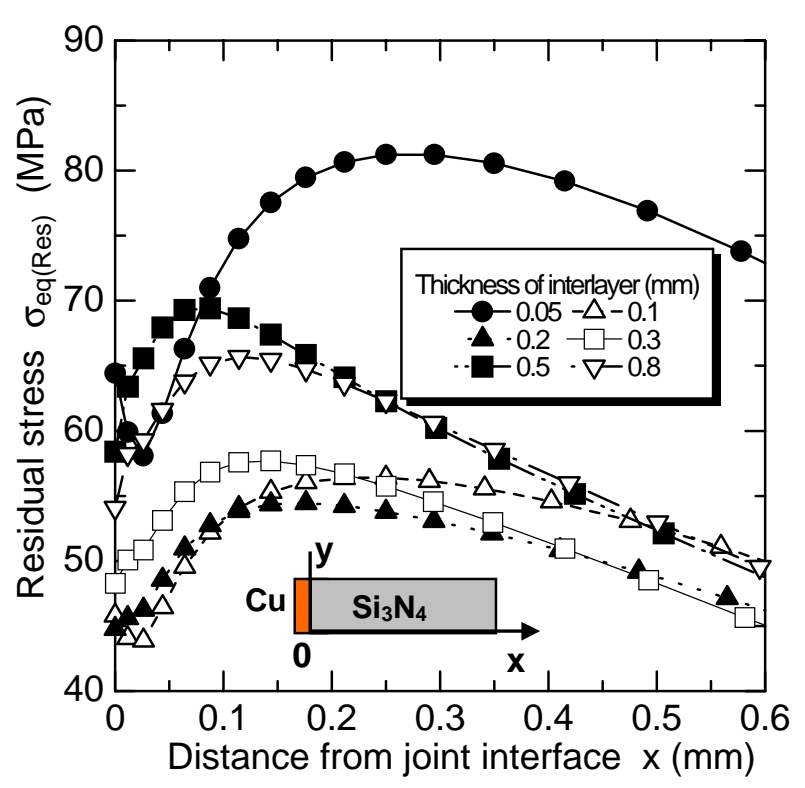

(a) Stress distributions against $\mathrm{x}$-axis direction on the surface of ceramics; $y=0, z=0$

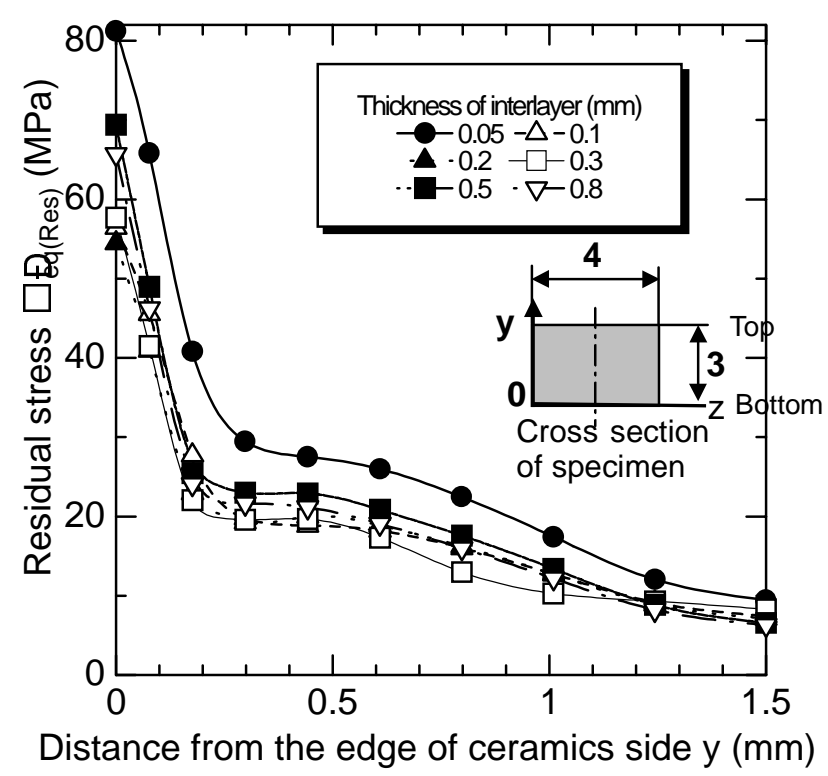

(b) Stress distributions against $y$-axis direction on the surface of ceramics; $\mathrm{x}=\mathrm{x} \mid \mathrm{o}_{\text {eq(Res)max }}, \mathrm{z}=0$

Figure 6: Distributions of equivalent residual stress in various interlayer thickness 


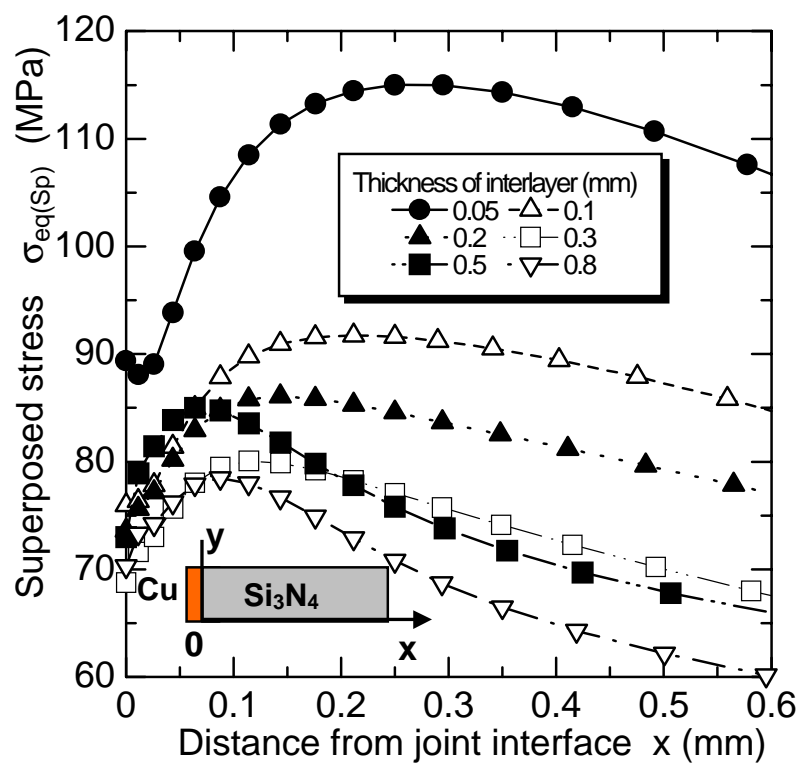

(a) Stress distributions against $\mathrm{x}$-axis direction on the surface of ceramics; $y=0, z=0$

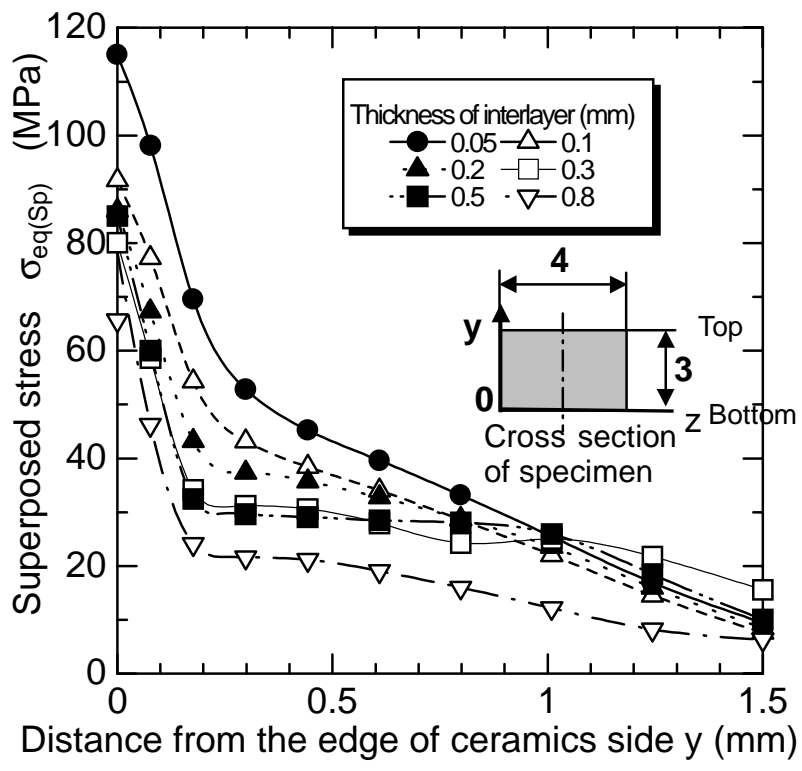

(b) Stress distributions against $y$-axis direction on

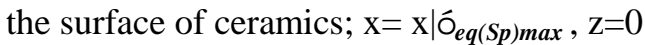

Figure 7: Distributions of superposed stress in several thickness of interlayer

Figure 6(b) shows the stress distribution against y-axis direction on the maximum residual stress position of (a). Maximum residual stress, ó eq(Res)max goes away from the interface with thinning interlayer thickness as shown as Figure 6(a). After the value decreases with thickening interlayer thickness, it is the lowest value at about $0.2 \mathrm{~mm}$ in thickness, and increases again. On the other hand, the residual stress distribution against yaxis direction indicates the maximum value, ó creases from the bottom to about $0.2 \mathrm{~mm}$ in depth, it decreases gradually.

\section{Superposed Stress Analysis}

Before superposed stress considering the residual stress redistributed by 4-point bend loading is analyzed, the standard load that the displacement of all interlayer thickness specimens becomes in a linear region was decided as $20 \mathrm{~N}$ (or nominal stress; $17 \mathrm{MPa}$ ) based on load-displacement curves corresponding to the all interlayer thickness specimens obtained by the FEM analysis. The superposed stress distribution was obtained by analyzing using the displacement, $\mathrm{u}_{e}$ corresponding to the standard load.

Figure 7 shows the distribution of the superposed stress, Ó $_{e q(S p)}$ to the each interlayer thickness. Figure 7(a) shows the superposed stress distribution against $\mathrm{x}$-axis direction from the interface of ceramics. Figure 7(b) shows the superposed stress distribution against $y$-axis direction on the maximum superposed stress position of Figure 7(a). Maximum superposed stress, ó $\boldsymbol{e q ( S p ) \text { max }}$ goes away from the interface with thinning interlayer thickness. The value decreases with thickening interlayer thickness. The behavior of the value differs from the behavior of an initial maximum residual stress, and shows the decreasing tendency. Figure 7(b) indicates that there is the maximum value, ó $e q(S p) \max$ on the specimen bottom, rapidly decreased from the bottom to about $0.15 \mathrm{~mm}$ against $\mathrm{y}$-axis direction before it decreased gradually.

Figure 8 shows the superposed stress distribution against zaxis direction on the maximum superposed stress position of Figure 7(a). In the interlayer thickness of $0.2 \mathrm{~mm}$ or less, the positions of the maximum superposed stress are both ends

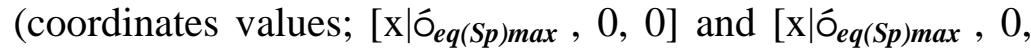
4]) of the lower side of the specimen. On the other hand, in the interlayer thickness of $0.3 \mathrm{~mm}$ or more, its position changes to a center (coordinates value; $\left[\mathrm{x} \mid \mathrm{o}_{e q(S p) \max }, 0,2\right]$ ). As the state of the stress distribution changes between 0.2

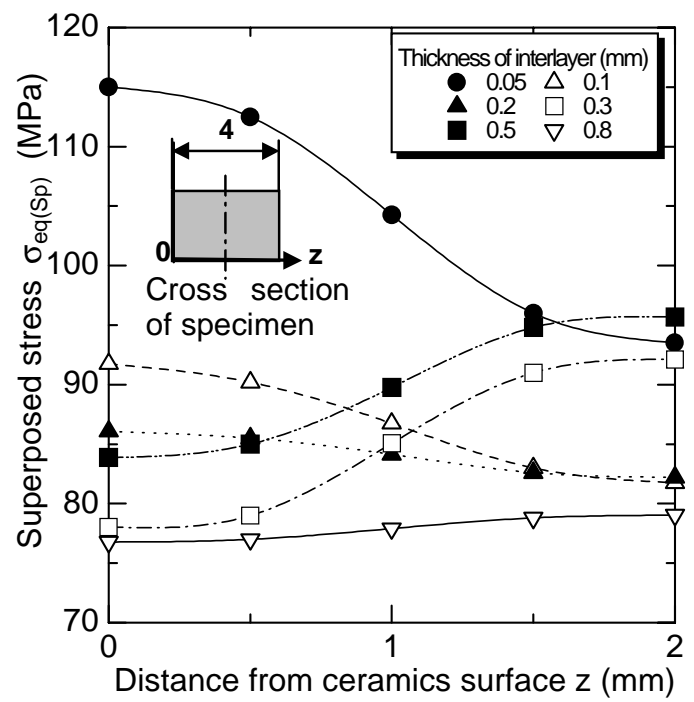

Figure 8: Distributions of the superposed stress toward width direction of specimen on the surface of ceramics side 
and $0.3 \mathrm{~mm}$ in the interlayer thickness, failure in the thin region of the interlayer thickness occurs from a nature flaw, which exists near both ends of the specimen, and failure in the case of thick region occurred from a potential defect, which exists near center.

\section{DISCUSSIONS}

\section{Fracture Morphology and Stress Intensity Factor}

To obtain steady joint strength, it is necessary to clarify the mechanism and criteria where IC and the CC type fracture occur. It paid attention to stress states of the interlayer thickness of 0.05 to $0.2 \mathrm{~mm}$. Here, it is assumed that a surface semicircle crack (crack length 2c) exists at the position of the maximum superposed stress for each interlayer thickness, as shown in Figure 9. Stress intensity factor for surface crack subjected to a distributed stress is calculated using Ref. [5]. When the stress intensity factor in the surface crack reaches the fracture toughness value of ceramics $\left(\mathrm{K}_{\mathrm{IC}}=6 \mathrm{MPa} \cdot \mathrm{m}^{1 / 2}\right)$, it is assumed that the specimen is failured rapidly. Considering that average flexural strengths of the each interlayer thickness are limit stresses to the fracture toughness value, Figure 10 shows relationship between the stress intensity factor distribution and $\mathrm{x}$-direction distance, when the superposed stress reach to the fracture toughness value on the position of the maximum residual stress (Fig.6(a)). The x-direction region of the superposed stress, which exceeds the fracture toughness value, is a little part of the interfacial neighborhood in the interlayer thickness of $0.2 \mathrm{~mm}$. On the other hand, in the interlayer thickness of $0.1 \mathrm{~mm}$ or less, the fracture starting points increase so that all regions at $\mathrm{x}$ direction position away from the interface may exceed the fracture toughness value. Moreover, IC type fracture does not occur easily because the stress field in interfacial neighborhood is lower than the stress distribution of the interlayer thickness of $0.2 \mathrm{~mm}$. Therefore, the increase of the fracture starting point can be referred as important factor for the occurrence of the CC type fracture in the interlayer thickness of $0.1 \mathrm{~mm}$ or less.

\section{Strength Estimation Considering Size and Position of Po- tential Defects and the Scatter Property of Strength}

It paid attention to joint strength occurring IC-type fracture of the interlayer thickness of $0.1 \mathrm{~mm}$ or more. In this discussion, the joint strength estimation is explained by using the interlayer thickness of $0.2 \mathrm{~mm}$. The superposed stress distribution of the joint interface neighborhood is calculated by loading a nominal bending stress to the joint model. Assuming surface crack length of 7 to 50 im against the stress distribution, the relation between $\mathrm{x}$-direction distance and stress intensity factor $K_{I}$ is led as shown in Figure 11. Where, this figure is shown by nominal bending stress $o_{b}$ of $250 \mathrm{MPa}$. After stress intensity factors to various nominal bending stresses are analyzed, the relation between a stress intensity factor and a nominal bending stress on arbitrary distance $x_{i}$, which is distance from the interface to the crack, can be arranged as shown Figure 12. When the stress inten-

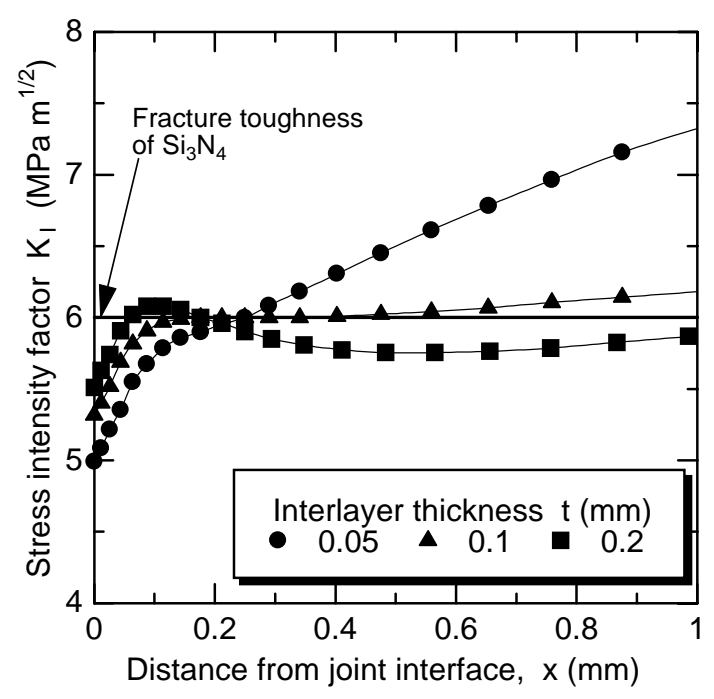

Figure 10: Region of fracture starting point in each interlayer thickness

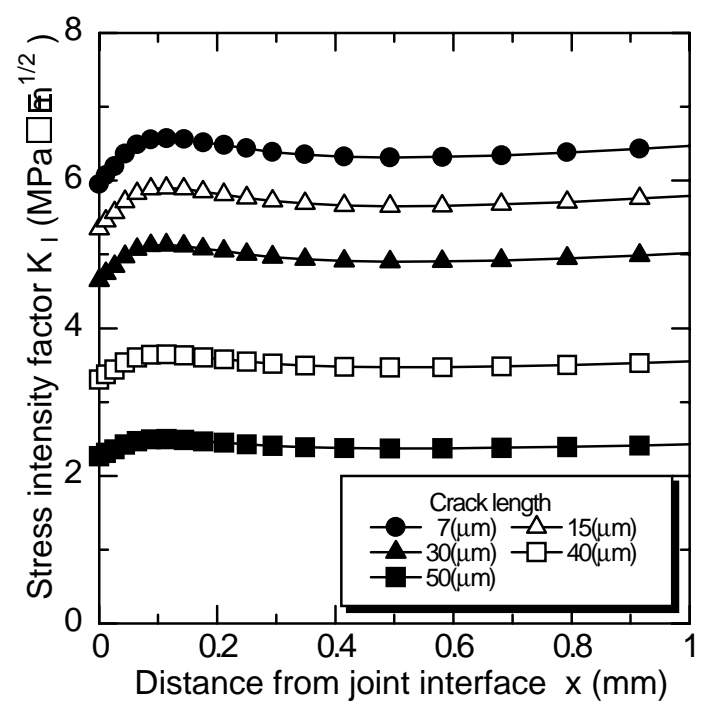

Figure 11: Relationship between $x$ direction distance and stress intensity factor $\mathrm{K}_{\mathrm{I}}$ with interlayer thickness of $0.2 \mathrm{~mm}$ and applied nominal stress of $250 \mathrm{MPa}$

sity factor in the surface crack reaches the fracture toughness value of ceramics $\left(\mathrm{K}_{\mathrm{IC}}=6 \mathrm{MPa} \cdot \mathrm{m}^{1 / 2}\right)$, it is 


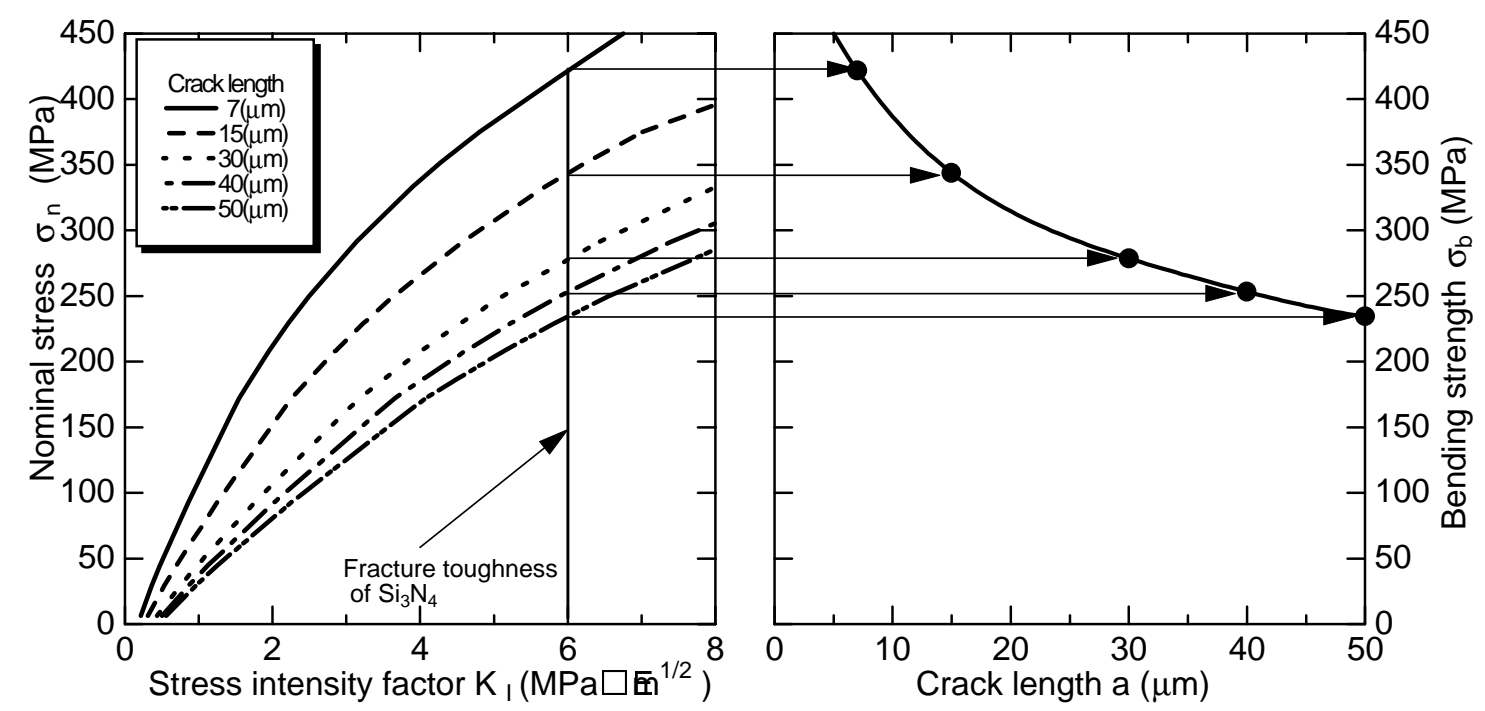

Figure 12: Relationship between a stress intensity factor $\mathrm{K}_{\mathrm{I}}$ and a nominal bending stress on arbitrary distance $x_{i}$

Figure 13: Relation of bending strength $o_{b}$ to crack length $a_{i}$ in arbitrary distance $x_{i}$

assumed that the specimen is failured rapidly. At this time, bending strength ó when each defect exists on distance $x_{i}$ is obtained. Therefore, the relation of bending strength ó to crack length $a_{i}$ in arbitrary distance $x_{i}$ is shown as Figure 13. Using this relation, the relation between the crack length and bending strength can be shown as following approximate equation on arbitrary distance $x_{i}$.

$$
\sigma_{b}\left(a_{i}\right)=A\left(a_{i}\right) \cdot f\left(a_{i}\right) \text { for position } x_{i}
$$

where, $A\left(a_{i}\right)$ is a coefficient.

In addition, when coefficient $A$ is arranged as a function of $x$, the relation of $A$ to arbitrary distance $x_{i}$ shows as Figure 14. The joint strength considering the position of a defect is given by

$$
\sigma_{b}\left(a_{i}, x_{i}\right)=A^{*}\left(a_{i}, x_{i}\right) \cdot f\left(a_{i}\right)
$$

where, $A^{*}$ is a coefficient considering defect size and its position. Therefore, if defect size and distance $x$ from the interface to its defect are clarified, the joint strength can estimate by using Eqn.3. Further, it is necessary to lead Eqn.3 of other interlayer thicknesses similarly.•

For the above-mentioned experiment results, the scatter of joint strength can be approximated as

$$
P_{f}=1-\exp \left[-\left(\frac{\sigma_{b}}{\sigma_{0}}\right)^{m}\right]
$$

by the two-parameter Weibull distribution. Here, as a simulation of bending strength, many defect size $a$, and its position $x$ are decided by random numbers respectively. And, estimation values of bending strength is obtained by using Eqn.3, which is the strength estimation equation from these two variables $a$, and $x$. In addition, the estimation values are plotted on Weibull probability paper in each interlayer thickness as shown Figure 15.

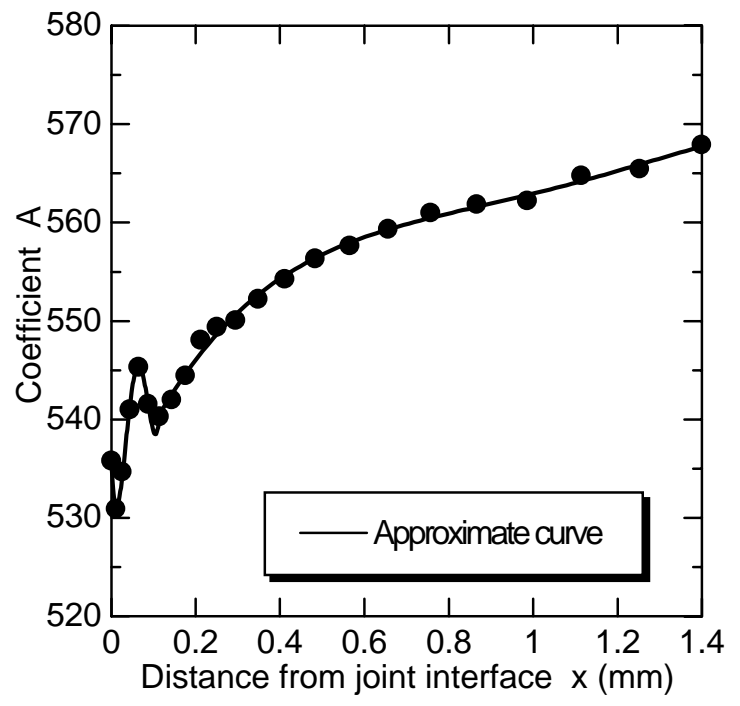

Figure 14: Relation of coefficient $A$ to arbitrary distance $x_{i}$

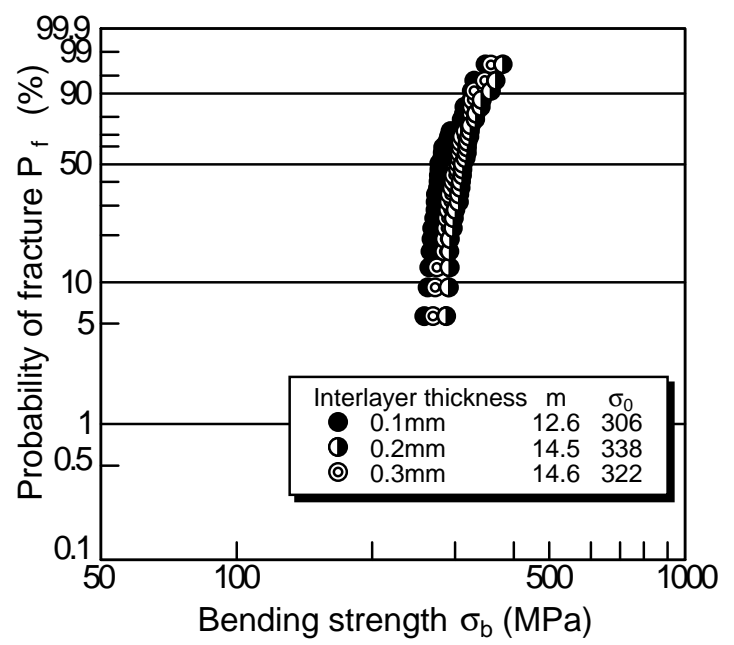

Figure 15: Weibull distribution of estimated bending strength 
The bending strength behavior to the each interlayer thickness, which estimated by using fracture mechanics and a probability theory technique based on this present analysis, is well agreed to the bending strength behavior of the experiment result. And, bending strength indicated the maximum value in the interlayer thickness of $0.2 \mathrm{~mm}$. In a word, an analytical technique suitable for deriving the optimum interlayer thickness could be developed. This estimation and analysis techniques are very useful as it is possible to apply to not only bending strength but also fracture strength of all joint structures. This technique is arranged to Figure 16 as a flow chart.

\section{CONCLUSIONS}

1. The failure in ceramic/metal joints structure is occurred from ultra neighborhood interfacial on the ceramics side. On the other hand, in the case of thin thickness, fracture is occurred from a little away from the interface on the ceramics, its strength is decreased sharply.

2. Maximum residual stress goes away from the interface with thinning interlayer thickness. After the value decreases with thickening interlayer thickness, it indicated the lowest value at about $0.2 \mathrm{~mm}$ of thickness, and increased again.

3. As one of causes where IC type fracture is generated, the $\mathrm{x}$ direction region of the superposed stress, which exceeds the fracture toughness value, is a little part of the interfacial neighborhood in the interlayer thickness of $0.2 \mathrm{~mm}$. On the other hand, as one of causes where CC type fracture is generated in the interlayer thickness of $0.1 \mathrm{~mm}$ or less, the fracture starting points increase so that all regions at $\mathrm{x}$-direction position away from the interface may exceed the fracture toughness value.

4. The bending strength behavior to the each interlayer thickness, which estimated by using fracture mechanics and a probability theory technique based on this present analysis, is well agreed to the bending strength behavior of the experiment result. Bending strength indicates the maximum value in the interlayer thickness of $0.2 \mathrm{~mm}$.

5. This analysis and estimation technology can suggest a useful indicator to the optimization of the selection of the material and the interlayer thickness in ceramic/metal joints structures with different construction materials, sizes and shapes.

\section{REFERENCES}

1. Kobayashi, H. (1989), J. Jpn. Weld. Soc. 58, 550.

2. Kobayashi, H., Arai, Y., Nakamura, H. and Nakamura, M. (1989) Trans. Jpn. Soc. Mech. Eng. 55, 750.

3. Okabe, N., ZHU, X., Hirobe, K. and Nakahashi, (2000), J.Soc. Mater. Sci. Jpn., 4.

4. Kobayashi, H., Nakamura, H., Matsunaga, J. and Takeshita, H. (1998), Annual Meeting of JSME/MMD, 98, 113 .

5. Stress intensity factors handbook, (1987) Eds.Murakami, Y. et al., 2, 723.
Analysis of residual stress of joint structures

Relation of stress intensity factor considering size and position of potential defects

Deriving of estimation equation of strength

$\sigma_{b}\left(a_{i}, x_{i}\right)=A^{*}\left(a_{i}, x_{i}\right) \cdot f\left(a_{i}\right)$

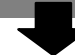

Calculation of $\sigma_{b}\left(a_{i}, x_{i}\right)$ which uses random numbers of $a_{i}$ and $x_{i}$.

$$
\begin{aligned}
& \text { Weibull statistic analysis } \\
& P_{f}=1-\exp \left[-\left(\frac{\sigma_{b}}{\sigma_{0}}\right)^{m}\right] \\
& \text { Decision of the optimum } \\
& \text { Finterlayer thickness } \\
& \text { estimation technique of opti- } \\
& \text { mum joint strength }
\end{aligned}
$$

stress with an external force 